\title{
Individual Achievement, Person-Major Fit, or Social Expectations: Why Do Students Switch Majors in German Higher Education?
}

\author{
Jasmin Meyer $^{1}$ (D) $\cdot$ Kathrin Leuze ${ }^{2} \cdot$ Susanne Strauss ${ }^{1}$
}

Received: 25 May 2020 / Accepted: 2 July 2021 / Published online: 14 July 2021

(C) The Author(s) 2021

\begin{abstract}
While a large body of research addresses both subject choice and student dropout in higher education, much less is known about switching the initially chosen major. Therefore, we ask why students switch their major in higher education and analyse this for the case of Germany, taking the timing and the degree of such switches (within and across subject groups) into account. Based on the extended rational choice framework, we identify three aspects that might explain switching majors: individual achievement in secondary education, a (mis)match between individual occupational interests and the content of studies and parental and peer judgement regarding the initial subject choice. We test the derived hypotheses by applying logistic regression models to representative data from the German National Educational Panel Study (NEPS), Starting Cohort 5. Our results indicate that the analysed aspects of individual achievement, person-major fit and social expectations affect switching majors, but their influence varies according to the degree and timing of the switch. While high-achieving students are more likely to switch majors, especially across disciplines and at a later stage in their studies, a mismatch in occupational interests mainly affects switching majors across broad subject groups. Finally, disapproval of the initial subject choice by parents and peers matters most for switches during the first two semesters and across academic disciplines.
\end{abstract}

Keywords Switching major · Individual performance $\cdot$ Person-major fit · Social expectations · Germany

Jasmin Meyer

jasmin.meyer@uni-konstanz.de

1 Department of History and Sociology, University of Konstanz, PO Box 26, 78457 Konstanz, Germany

2 Friedrich-Schiller-University Jena, Room 2.86, Carl-Zeiß-Platz 3, 07743 Jena, Germany 


\section{Introduction}

During recent decades, enrolment in higher education has risen strongly in all industrialized countries (OECD, 2019: 50). This is also the case in Germany, where the share of the respective age cohort with a higher education entrance certificate increased from $26 \%$ in 1995 to 54\% in 2017 (Statistisches Bundesamt, 2018). Despite this ongoing expansion in higher education, however, many students do not receive a degree in the major they originally enrolled in (OECD, 2019: 208). Estimates for Germany for 2010, for example, indicate that about $39 \%$ of university students and about $21 \%$ of students at universities of applied sciences either switched majors or dropped out from higher education altogether (Heublein et al., 2012). Within this group, up to $30 \%$ of all students switched from the major they had initially chosen (Heublein et al., 2008).

Previous research on student retention, however, has focused either exclusively on student dropout or jointly on dropout and switching majors, both in Germany (e.g. Blüthmann et al., 2008; Fellenberg \& Hannover, 2006; Heublein, 2014; Heublein et al., 2012, 2017; Ishphording \& Wozny, 2018) and elsewhere (e.g. Belloc et al., 2011 for Italy; Hovdhaugen, 2009 for Norway; Robinson, 2004 for Australia). In contrast, very few studies exclusively address switching majors. These studies mostly do not examine switching majors in general (as exceptions, see Astorne-Figari \& Speer, 2019 for the US; Diem, 2016 for Switzerland), but either focus on particular groups of subjects (King, 2015; Ost, 2010), consider specific groups of students (Riegle-Crumb et al., 2016; Tieben, 2020), or examine single higher education institutions (Belloc et al., 2011; Bornmann \& Daniel, 1999). As a consequence, most of these studies have theoretical explanations tailored to their specific research topic but do not develop a theoretical framework applicable to switching majors in general. Moreover, representative studies on the higher education system as a whole are largely missing, especially regarding the German case. This paper, therefore, investigates possible factors that may explain why students enrolled in a German higher education institution switch their initially chosen major.

Germany is an interesting case to examine on this topic since switching majors is institutionally more restricted than in more open higher education systems, such as the US (Wright, 2018). In German higher education, students enrol in a specific major or combination of majors and thus have to reapply again when switching their major. Moreover, there are restricted admissions for a lot of majors at German higher education institutions, which are, for example, based on specific grades obtained in the higher education entry qualification (Finger et al., 2018). Therefore, students have to comply with these admission criteria when selecting a new major. These restrictions are very similar to those in many Asian countries, Chile or some other European countries like Spain and Turkey (Bordon \& $\mathrm{Fu}, 2015$ ), but very different to open major choice systems, such as the US (Bordon \& Fu, 2015), which allows students to start with an undeclared major and to easily switch their major during studies (Bridet \& Leighton, 2015; Wright, 2018).

Accordingly, switching majors in Germany is likely to have negative consequences for students, such as extending their period of study, a probable loss of human capital investment, and an increased risk of dropout (Wolter et al., 2014). It might also entail macroeconomic costs, especially if higher education is mainly state financed (as is the case in Germany), and thus switching majors may lead to a loss of public investment (Diem, 2016). At the same time, switching majors might have positive consequences, since it gives students the opportunity to revise an unsuitable initial subject choice (Bornmann \& Daniel, 1999; Diem, 2016). These positive consequences have been shown for open major systems such 
as the US, and indicate that students switching their major even show higher graduation rates than students persisting in their initially chosen major (Liu et al., 2021; Yue \& Fu, 2017). For higher education systems where changing majors involves a reapplication there is, however, not yet any evidence on how these factors drive such decisions.

The consequences of switching majors may depend on the degree and timing of such switches, which is why it is important to differentiate between different types of major changes. Regarding the degree of switching, we can differentiate between "low-cost" and "high-cost" major switches (Arcidiacono, 2004). If students switch their major within broader categories of academic disciplines (for example from sociology to political sciences in the broader field of social sciences), this might involve less effort and fewer costs, since course requirements are similar to those of the initial major and achieved credit points can be transferred relatively easily to the new course of study. In contrast, if students completely revise their initial subject choice and switch between broader categories of academic disciplines (for example from physics to history), the loss of human capital investment is likely to be larger. This is in line with assumptions of Astorne-Figari and Speer (2019), who first examined the distance of major switches in order to distinguish between major changes and only smaller corrections of major choice.

The timing of switching refers to switches taking place at an early or late stage of higher education studies. In this regard, studies from the US indicate that early major switches have no negative impact on students' success in higher education (Foraker, 2012; Liu et al., 2021), while switches taking place after the second year are correlated with lower grades and graduation rates, but also with longer times until graduation (Foraker, 2012). In Germany, the negative consequences of late switches might be aggravated due to the system of state subsidies for students of low-income families, since these are only paid if switching majors take place during the first three terms. ${ }^{1}$ We thus contribute to the existing literature by systematically differentiating between the degree and timing of switching majors, as this latter aspect in particular has not been a focus of previous research.

In the following section (Sect. "Previous Research"), we briefly summarize the state of previous research on switching majors before presenting our theoretical considerations and hypotheses (Sect. "Theoretical Considerations"). These are examined empirically based on data from the student cohort of the German National Educational Panel Study (NEPS SC5), a nationwide representative study following first-year students during the first six years of their higher education trajectory. We describe the dataset, operationalizations, and methods applied in Sect. "Data, Operationalizations, and Methods" before presenting our results from logistic regression models in Sect. "Results". The article concludes with a discussion on the empirical results and implications for further research (Sect. "Conclusion").

\section{Previous Research}

Very few prior studies have exclusively addressed the topic of switching majors in higher education. These studies mostly do not examine switching majors in general (for exceptions, see Astorne-Figari \& Speer, 2019 for the US; Diem, 2016 for Switzerland), but either focus on particular groups of subjects, student groups, or higher education institutions. Two studies from the US examine switching majors from particular subject groups:

\footnotetext{
${ }^{1}$ According to Section 7 Paragraph 3 of the German Federal Education Promotion Act (BAföG).
} 
King (2015) examines switching majors from STEM fields in comparison to other subjects and Ost (2010) looks at switching majors in life and physical sciences. Regarding student groups, Riegle-Crumb et al. (2016) investigate the switching of majors by US students in gender-atypical subjects, while Tieben (2020) examines the switching of majors by nontraditional students in Germany, who graduated from vocational training before entering higher education. Focusing on single higher education institutions, Belloc et al. (2011) examine switching majors in Italy and Bornmann and Daniel (1999) do so for Germany. So far, no representative study on switching majors exists for the German system of higher education, which is the focus of the present paper.

Generally, it is important to note that the definition of what is considered a major switch varies strongly between different studies. While some studies investigate switches between different higher education institutions (Hovdhaugen, 2009; Ishitani \& Flood, 2018), others identify switching majors as a potential pathway to graduation (Robinson, 2004) or examine switches to other departments within the same higher education institution (Belloc et al., 2011; Bornmann \& Daniel, 1999). Others investigate subject persistence rather than switching majors (Ost, 2010) or they investigate the degree of switching by considering aspects of the original major and the one the student has switched to (Astorne-Figari \& Speer, 2019; Riegle-Crumb et al., 2016). In this study, we examine switching majors irrespective of whether the switch takes place within or between higher education institutions. Rather, we consider two different aspects related to switching majors: the degree and the timing of change. Regarding the degree of switching, we compare students switching their major within or across broad academic disciplines. The timing of switching differentiates between switches taking place at an early or at a late stage of the course of study.

As regards explanations for switching majors, three broad strands can be identified in the literature: aspects of individual achievement, the person-major fit, and social expectations of parents and peers. First, previous studies indicate that achievements in secondary schooling and in higher education seem to matter when switching majors. Students with better grades in high school, with a better performance in the course of higher education, or who are actively involved in their studies and show higher effort have a lower probability of switching faculty or their initial major (Astorne-Figari \& Speer, 2019; Belloc et al., 2011; Hovdhaugen, 2009; King, 2015; Ost, 2010). We will therefore consider student achievement in high school as an explanatory factor. In particular, we consider the final grade of students' higher education entry examination, which captures several aspects that are important for academic success, not only in terms of cognitive performance, but also as regards study skills and goals (e.g. Schlücker \& Schindler, 2019).

Second, if the characteristics of the first and newly chosen major are considered, it seems that students generally seek to achieve a better person-major fit when switching their major. Astorne-Figari and Speer, (2019), for example, consider the gender and racial compositions of majors as well as their competitiveness and course requirements. They find that, in general, students switch to majors with course requirements that are a better match for their abilities and their own characteristics in terms of race and gender (see also Diem, 2016 for Switzerland). Moreover, women are more likely to leave more competitive majors than men (Astorne-Figari \& Speer, 2019). Since individuals seek to find the best possible match between their own occupational interests and their environment (Holland, 1997), we will consider this further aspect of person-major fit as an explanatory point of reference. More specifically we investigate whether the possible (mis)match between students' occupational interests and the content taught in their initial major explains switching.

Finally, significant others, especially parents and peers, play an important role when switching majors. First, the parental judgement of the subject choice seems to matter. For 
example, young women are more likely to switch their major should their parents disagree with their career aspirations (Li \& Kerpelman, 2007). Furthermore, the social and academic integration with fellow students has a lasting impact on persisting within a major. Students who are better socially integrated in their degree courses are less likely to switch majors (Ishitani \& Flood, 2018). In terms of academic integration, low-performing students are more likely to persist if they are surrounded by high-achieving peers (Ost, 2010). ${ }^{2}$ Since the data used in this study do not allow us to examine the effect of social integration or the achievement of peers directly, we measure both, parental and peer influences by their (dis-)agreement with students' original subject choice and how this affects students' decision to switch majors.

In sum, we assume individual achievement, the (mis)match between students' occupational interests and the content taught in their initial major, and the expectations of students' parents and peers to have an impact on the switching of majors in higher education. Since none of the above-mentioned studies considers all of these aspects, we take them into account simultaneously when analysing switching majors. In addition, sociodemographic characteristics have been shown to matter, in particular gender, migration and parental education background, and having finished vocational training before studying. The results of previous research indicate that women (Astorne-Figari \& Speer, 2018; Belloc et al., 2011) and students from low-income families (Belloc et al., 2011; Ishitani \& Flood, 2018) have an increased risk of switching major, while students that graduated from vocational training before entering higher education (Tieben, 2020) are less likely to do so. Results on the effect of race/ethnicity are mixed, since a study on the US indicates that Black and Hispanic students are more likely to switch their major (Astorne-Figari \& Speer, 2018), while other studies on the US (Ishitani \& Flood, 2018), Italy (Belloc et al., 2011) and Switzerland (Diem, 2016) find that immigrant or foreign students switch less often. Since none of these studies offer a theoretical explanation for these results, we decided to take those sociodemographic aspects as control variables into account.

\section{Theoretical Considerations}

Since there are only few studies dealing with switching majors in higher education, we consider and apply the theoretical perspectives and existing research on two related topics to the phenomenon of switching majors: research on (initial) subject choice, and studies on higher education dropout. Theoretically, students may decide to switch majors because of bad study conditions and their dissatisfaction with aspects of their originally chosen major. Moreover, students compare the different characteristics of the initial major to what they expect to be the characteristics of their second choice of subject. In this paper, we focus on explanatory factors relating to the originally chosen major to compare students switching majors with students who are still enrolled in or who graduated from their originally chosen major. ${ }^{3}$

\footnotetext{
${ }^{2}$ Achievement is measured by several indicators, like the SAT scores or GPA of different 1st year courses.

${ }^{3}$ Considering aspects of the second major would require focusing the analysis exclusively on students who have switched majors, since only these students have a first and a second major to be compared (see Astorne-Figari \& Speer, 2019). We also do not compare students switching majors to students who have dropped out completely, as in the dataset used no clear-cut differentiation between permanent student dropout and temporary study interruptions can be made (Ishphording \& Wozny, 2018) and student dropout might be highly biased by panel attrition.
} 
To conceptualise how aspects of individual performance, the person-major fit, and perceived social expectations of parents and peers might affect switching majors, we apply a sociological rational choice framework ${ }^{4}$ that has been developed for explaining educational choices (Erikson \& Jonsson, 1996; Jonsson, 1999) and that has been applied to both subject choices and student dropout. From this perspective, when deciding whether to stay or to switch, students rationally consider their probabilities of success in the initial major and weigh the anticipated benefits and costs of staying versus leaving. ${ }^{5}$ We will argue in the following that a student's school achievement is one possible dimension affecting the probability of mastering the performance requirements of the initial major successfully. A good match between individual occupational interests and the interests met by particular subjects is considered a possible benefit of staying in the initially chosen subject. Finally, meeting parental and peer expectations are possible dimensions to lower the social costs when choosing a particular subject. Switching majors can thus be considered as revising the choice of the original field of study, which was made under incomplete information (Altonji et al., 2012). In the following, we elaborate these expectations in more detail and discuss whether the assumed mechanisms should have a stronger impact on students switching majors across or within subject groups (degree of switching) or at an early or late stage of their study (timing of switching).

Switching majors should be affected by a student's expected probabilities of successfully graduating from the initially chosen major. From the perspective of rational utility maximization, students assess their school achievements in a particular domain both objectively through grades and by subjective evaluations and choose a major they assume they can successfully master, which thus offers the highest probability of success (Becker et al., 2010). In doing so, they consider their strengths in single subjects, such as mathematics or science, but also compare their relative abilities across domains (Jonsson, 1999). Previous research on initial subject choices has demonstrated that individuals use their objective schooling achievements in different domains to assess the probability of succeeding in particular subject groups (Becker et al., 2010; Hägglund \& Lörz, 2020; Mann \& DiPrete, 2016). Moreover, subjective evaluation of strengths and weaknesses in particular domains seems to matter for the initial subject choice (Hägglund \& Lörz, 2020; Mann \& DiPrete, 2013; Werfhorst et al., 2003). Finally, a large number of studies show that high achievement in secondary school and in higher education decreases the risk of dropping out from higher education (Isleib et al., 2019; Ishphording \& Wozny, 2018; Robbins et al., 2004; Wolter et al., 2014).

If we apply this perspective to switching majors, we can derive two competing hypotheses. Pupils at the end of secondary school do not have precise information on the performance requirements of particular subjects and whether they will be able to meet them.

\footnotetext{
${ }^{4}$ Rational choice theory is prominent in many social sciences (see Chai, 2001 for a discussion). We apply a sociological perspective that considers how perceived costs, benefits and probabilities of success affect the utility and thus choice of an educational alternative (Erikson \& Jonsson, 1996). Other types of rational choice models, such as expectancy-value theories (e.g. Eccles [Parsons] et al., 1983; for an empirical overview see Eccles, 2011) which are prominent in social psychology also discuss costs and benefits, but more strongly refer to individual values attached to them. Since the data at hand do not allow us to investigate these values, we base our theoretical explanations on the sociological readings of rational choice theory.

5 Since we focus on explanatory factors related to the originally chosen major, we discuss the respective rational choice components in relation to staying in the original major and not for leaving it, which is less common than focusing on a change through educational choices. In this perspective, the benefit of staying is equal to the cost of switching and vice versa.
} 
Only after entering higher education in a particular subject can students have a better idea of what type of exams they have to take and how well they can perform in comparison to their fellow students. These experiences might change their initial evaluation of the probability of success. An objective evaluation in the sense of school grades might serve as a signal of how well performance requirements can be met. In the case of low final school grades, students not only have a higher probability of dropping out completely from higher education but also have a higher probability of switching majors (Astorne-Figari \& Speer, 2019; Belloc et al., 2011; Hovdhaugen, 2009), possibly to subjects with lower performance requirements (Astorne-Figari \& Speer, 2019). Therefore, we expect that lower achievement in secondary education increases students' probability of switching majors (H1a).

However, due to the particular situation in the German higher education system, many subjects have a restricted admission based on students' average achievements in secondary education (Finger et al., 2018). As a consequence, students with lower final average grades in secondary education have a smaller range of potential subjects in higher education to choose from-both at the moment of the initial decision and at the moment of revising this decision. In contrast, students with better average final grades have more options to choose from when intending to revise their initial subject choice. Accordingly, their evaluation of the criteria for success in a different major should be higher than for students with lower final grades. Therefore, - as a counter hypothesis to hypothesis 1a-we expect that higher achievement in secondary education increases a student's probability of switching majors (H1b).

Regarding the degree and timing of switching majors, we assume that school achievements should matter more strongly for switches across rather than within broad disciplines and early in their studies. In both cases, students will already know whether they meet specific course requirements during the first two semesters. Since course requirements may be rather similar within broad subject groups, school achievements should matter in particular for switching majors across disciplines and switches taking place in the first two semesters.

The expected benefits of a subject comprise its suitability for life and career plans (Jonsson, 1999), but also the value young adults attach to specific occupational contents (Eccles, 1994). Building on Holland's theory of vocational choices (1997), we assume that individuals seek to find the best possible match between their own occupational interests ${ }^{6}$ and their environment, i.e. the content taught in the particular major they are enrolled in. According to Holland (1997), individuals seek to achieve a match between their occupational interests and different occupational groups by utilizing occupational stereotypes and public discourses. This implies that members of an occupation or subject display a similar interest structure (Holland, 1997), but also that the content of studies matches some interest structures better than others (Nagy, 2007). Accordingly, a good match between individual occupational interests and the interests met by particular subjects can serve as one possible benefit of staying in the initially chosen subject.

Previous research shows that Holland's occupational interests are a strong predictor of students' major choices, both in Germany (Hägglund \& Lörz, 2020; Nagy, 2007; Ochsenfeld, 2016) and elsewhere (Porter \& Umbach, 2006). In the context of Germany, Nagy (2007) was the first to apply this concept to the transition from secondary to higher

\footnotetext{
${ }^{6}$ In the so-called RIASEC model (Holland, 1997), occupational interests are divided into six categories. Apart from artistic (A), social (S), and enterprising (E) interests, realistic interests (R) relate to practical and technical orientations, investigative interests (I) relate to intellectual and scientific tasks, and persons with conventional interests $(\mathrm{C})$ like working with written records and numbers.
} 
education and to demonstrate its importance for subject choices. Only a handful of studies investigate the role of occupational interests on student dropout and show that a good match between students' occupational interests and the content of the subject enrolled in decreases the dropout risk (Allen \& Robbins, 2008, 2010 for the US; Nagy, 2007 for Germany).

If we apply this perspective to switching majors, we can assume that pupils at the end of secondary school do not have precise information on the content of particular fields of study. Rather, they derive their knowledge from stereotypes about specific subjects and make their initial subject choices in higher education according to them. Only after entering higher education are they able to evaluate whether their individual occupational interests are actually met by the content taught in the respective major. Accordingly, we expect that students are more likely to switch majors if their individual interests do not match the dominant content taught in their initially chosen major $(\mathrm{H} 2)$.

We again assume that a mismatch between individual occupational interests and the content of a particular subject should matter more strongly for switches across broad disciplines and for early switches. Regarding the degree of switches, students are more likely to find a better match if they decide to switch to a major that is not related to the one they originally chose and therefore belongs to a different subject group. Moreover, the longer students stay in their originally chosen major, the better they might accommodate their individual interests to the content of the subjects, thus lowering the likelihood of possible mismatches. As a consequence, mismatches between occupational interests and the content taught within the originally chosen major should increase the likelihood of switching majors, particularly during the first two semesters.

Finally, perceived costs should matter for explaining switches between majors. Theoretically, these costs might arise in the form of both monetary ${ }^{7}$ and social costs (Erikson \& Jonsson, 1996; Jonsson, 1999). We focus here on the aspect of social costs deriving from significant others, such as parents and peers. In this regard, studies on initial subject choices point toward the influence of parents' socioeconomic background and parental expectations (Lörz et al., 2011; Raabe et al., 2019; Werfhorst et al., 2001). Regarding peer influence, students in general adjust their subject preferences to those of their friends (Raabe et al., 2019). Moreover, good social integration with peers and faculty members (e.g. Ishphording \& Wozny, 2018; Klein, 2019; Meyer \& Strauß, 2019) or a perceived positive study culture (Severiens \& Dam, 2012) reduce a student's dropout risk.

When applying this perspective to switching majors, a student's initial subject choice often follows the expectations of their parents, either in terms of the subject's gender composition or in terms of the social status achieved by graduating in a specific subject (Lörz et al., 2011; Werfhorst et al., 2001). Yet if students do not choose a major in accordance with parental expectations, social costs might arise in the form of parental disagreement or low parental support, which may also include a lower level of financial support. This in turn might increase the likelihood of students switching majors in a direction more in line with parental expectations. In a similar vein, peers are assumed to affect social costs related to initial subject choices by supporting (or not supporting) the choices made. According to Raabe et al. (2019), young adults value their friends' opinions and discuss their preferences for subjects. If peers disapprove of a student's initial subject choice they might sanction such nonconforming behavior. Accordingly, we expect that students are more likely to

\footnotetext{
7 Monetary costs can also be important, but within the dataset used they are not measured at all relevant times.
} 
switch majors if their initial subject choice does not conform to parental or peer expectations (H3).

These cost considerations should again matter more strongly for switches across broad subject categories and for early switches. Regarding the degree of switching, switching majors within broad categories might not suffice to regain parental or peer support if parents and peers strongly disagree with the initial subject choice. Moreover, students are likely to be more strongly focused on the approval of their parents and former school friends at the beginning of their studies. At a later stage, they are already socialized into their field of study and social integration in higher education should matter more strongly when deciding whether to leave their study programme. Thus, social costs should be particularly relevant for switches across broad subject categories and at an early stage of higher education studies.

To sum up, we expect the different aspects of individual performance, the person-major fit, and perceived social expectations of parents and peers to predominantly affect substantial switches taking place across broad subject groups and switches taking place at an early stage of the course of study.

\section{Data, Operationalizations, and Methods}

To test our hypotheses empirically, we use the German National Educational Panel Study (NEPS) (Blossfeld et al., 2011), ${ }^{8}$ which follows the educational pathways of six different age cohorts from early childhood (Starting Cohort 1) to adulthood (Starting Cohort 6). The analysis is based on Starting Cohort 5, a cohort of first-year undergraduate students who enrolled for the first time in a German higher education institution in the winter term 2010/11 (FDZ-LIfBi, 2018). The survey started with a sample containing 17,910 students, with an oversampling of students in teacher education and those attending private higher education institutions (FDZ-LifBi, 2018). Our analyses include the first 11 waves taking place between the winter term 2010/11 and the summer term 2016, which means following first-year students for up to 6 years or 12 semesters during their higher education careers. As a consequence, most students finished at least their first degree during the period of observation.

Of these first-year students, 5704 left and did not return to higher education during the period of observation. These (temporary) dropouts were excluded from the analyses, since the data do not allow differentiating between dropping out temporarily or dropping out permanently (Ishphording \& Wozny, 2018) and they are strongly biased because of high panel attrition rates. The sample of the remaining 12,206 students was further reduced due to missing values on important variables, ${ }^{9}$ which were excluded by listwise deletion and

\footnotetext{
8 This paper uses data from the National Educational Panel Study (NEPS): Starting Cohort First-Year Students, https://doi.org/10.5157/NEPS:SC5:10.0.0. From 2008 to 2013, NEPS data was collected as part of the Framework Program for the Promotion of Empirical Educational Research funded by the German Federal Ministry of Education and Research (BMBF). As of 2014, NEPS is carried out by the Leibniz Institute for Educational Trajectories (LIfBi) at the University of Bamberg in cooperation with a nationwide network.

9 The number of missing values is largest for the variables regarding judgement by parents and peers (1977), which results from two different recruitment processes of the sample: the largest part of the sample was recruited in first-term lectures at higher education institutions, where students filled in a short questionnaire including the items on parental and peer expectations. A smaller part of the sample of students not attending these lectures was recruited via postal questionnaires, which did not include these items (Stein-
} 
resulted in an analytical sample of 9006 students in total. To make sure that our independent variables precede our dependent variable, all independent variables used in the models were measured in the first wave, i.e. the first semester in higher education. To deal with the problem of sample selection bias and panel attrition, we applied weights that take into account the sampling design and panel mortality (Zinn et al., 2017).

The dependent variable switching major is based on students' self-reported information that they have switched majors since starting their study or since participating in the last survey wave. ${ }^{10}$ Majors were measured using the classification of the German Federal Statistical Office (Statistisches Bundesamt, 2012: 443ff.), which means we are able to distinguish between 78 fine and nine broad subject categories. On the basis of these subject categories we are able to measure switching majors in two different ways. First, we define major switching as a transfer from the initially chosen major to any new major based on the 78 subject categories. Second, we differentiate between students switching majors within the same broad study group and those switching to another broad study group. To do so, we collapse the 78 subjects into nine broader study groups (for the assignment of the single subjects to the broad study groups, see Table 2 in the appendix) and identify whether students switched majors either within or across the broad categories. Since the information on switching majors was measured from Wave 2 up to Wave 11 in every second survey, we are also able to identify the timing of switching majors. We differentiate between students switching majors at an early stage of their study (in the first or second semester) ${ }^{11}$ and those deciding to do so at a later stage (third semester or later). Since we have no information about the actual higher education institutions students are enrolled in, a major switch can take place within the same institution or after switching between institutions.

In our first model we compare students who switched majors in general $(1, \mathrm{~N}=1247)$ with students still enrolled in or having graduated from their originally chosen major $(0$, $\mathrm{N}=7759$ ). In our second and third model we compare students who switched majors across $(\mathrm{N}=850)$ or within $(\mathrm{N}=397)$ broad subject groups (1) with students still enrolled in or having graduated from their originally chosen major (0). In our fourth and fifth model we compare students switching majors in the first or second semester $(\mathrm{N}=655)$ or in the third semester or later $(\mathrm{N}=592)$ (1) with those still enrolled in or having graduated from their originally chosen major (0). Overall, $13.8 \%$ of the students switched majors during the six years following their initial enrolment in higher education, which is slightly higher than the estimated figures of Heublein et al., (2012: 46-50). Of those who switched their major, $47 \%$ did so within their first two semesters and about two-thirds of them switched to another broad subject group. Students enrolled in larger subject groups in particular (such as linguistics and cultural studies) often switch majors within the same subject group (see Table 3 in the appendix).

\footnotetext{
Footnote 9 (continued)

wede \& Aust, 2012: 30). Missing values on the other variables are all below 5\%, with the highest numbers found for final grades in upper secondary education (553), subject of choice (463), and academic background of parents (180).

${ }^{10}$ Empirically, students can report that they switched their major multiple times, but we only consider the first reported switch since most students only switch once.

11 Students lose their right to state subsidies when major switches take place after the third semester. Due to the study design we cannot measure this specific point of time since switches are only reported on a yearly base in every second wave. Therefore, we measured early switches as those taking place during the first two semesters, which is also supported by official statistics for Germany, according to which most major changes take place in the first year of higher education studies (Statistisches Bundesamt, 2020).
} 
Our first independent variable, student's achievement in secondary education, is measured by the average final grade of the higher education entry certificate in upper secondary education, which ranges in Germany from 1.0 (best mark) to 4.0 (lowest mark). ${ }^{12}$ To facilitate interpretation of this variable, we rescaled the variable: higher values now point toward a better performance in secondary education.

Person-major fit is operationalized by a possible (mis)match between individual occupational interests and the content taught in the initially chosen major. Individual occupational interests are measured with the "Interest Inventory Life-Span" for adults (IILS-II), based on the instrument developed by Bergmann and Eder (1999), containing three items per interest domain. The resulting six indices range from 1 to 5 and measure a student's realistic, investigative, artistic, social, enterprising, and conventional interests at the beginning of their higher education studies. To operationalize a possible (mis)match with the content of subjects, we compare those individual interests to the occupational interest domain most relevant in each subject category, as identified by Nagy (2007) and Bergmann and Eder (1999) (see Table 4 in the appendix). The derived variable includes three categories indicating whether a student's occupational interest in the most relevant domain per subject is at a high, average, or low level. Since means and standard deviations vary strongly across interest domains, we define the interest level to be low if a student's interest has a value below the 50th percentile in the sample, average for values between the 50th and 75th percentiles, and high for values above the 75th percentile (see Table 5 in the appendix). ${ }^{13}$ The resulting variable comprises three categories, representing a bad $(0$, ref. category), good (1), or very good (2) match between students' individual occupational interests and the content of their major.

Finally, perceived parental and peer expectations are operationalized with parents' and peers' (dis)agreement with students' initial subject choice. For doing so, students were asked whether their parents or friends approved of their subject choice, with answers ranging from " 1 " (applies completely) to "5" (does not apply at all). Thus, higher values indicate stronger disapproval on the part of parents and peers regarding a student's initial subject choice.

We further control for the following factors that have been shown to affect switching majors as well as our main explanatory variables (see Sect. "Previous Research"): student's gender $(1=$ women, $0=$ men $)$, migration background $(1=$ up to the third generation, $0=$ no migration background), ${ }^{14}$ parental education background $(1=$ at least one parent with tertiary education (ISCED-97 5a, 6), $0=$ no parent with tertiary education), and previous vocational training qualification $(1=$ yes, $0=$ no). Moreover, we control for the two types of higher education institutions existing in Germany ( $1=$ universities, $0=$ universities of applied sciences), since students drop out more often from universities (e.g. Isleib et al., 2019), which might also be the case for major changes. Finally, we consider whether students have enrolled in the subject of their choice $(1=$ yes, $0=$ no), which has been shown

\footnotetext{
${ }^{12}$ We could neither use objective information on a student's achievement in higher education nor the subjective assessment of a student's performance, since this information was collected in the second wave of the survey (in the second and at the beginning of the third term) for the first time. Accordingly, students switching majors within the first two semesters would give information on their achievements in the new major rather than the one initially chosen.

13 We also used other thresholds to check for the robustness of this measure (the 40th and 60th percentiles), which did not change the results (not shown; available upon request).

14 As a robustness check, we run the models with a migration background up to the second or the third generation, but we could not find a difference.
} 
to reduce students' dropout risk (e.g. Ishphording \& Wozny, 2018) and could thus also explain why students switch their major. A descriptive overview of all variables can be found in Table $1 .^{15}$

Due to the binary response variable for switching majors, we estimate logistic regression models. As described above, we use five different dependent variables, resulting in five different models: (1) switching majors in general; (2) switching majors across broad subject categories; (3) switching majors within broad subject categories; (4) switching majors at an early stage during the first two semesters; and (5) switching majors at a later stage (see Table 6 in the appendix for the full models). In each of these models, students switching majors are compared to students still enrolled in or having graduated from their initially chosen major, which results in different sizes of the analytic sample depending on the dependent variable. Coefficients are presented as average marginal effects (AMEs), which can be interpreted as percentage point differences in the probability of switching majors for a one-unit change of the predictors (Mood, 2010). To take different change rates per subject category and further unobserved subject characteristics into account, we include a dummy variable for each category of the fine subject classification (subject fixed effects) in all models.

\section{Results}

How do school grades, the fit between personal occupational interests and the content that is taught in the initially chosen field of subject, and parental and peer expectations affect switching majors? To answer these questions empirically, we first examine the distribution of the explanatory variables for the total sample and then separately for the four groups of switches (across/within broad categories, early/late switches) (Table 1).

For the final grades in upper secondary education we cannot observe considerable differences between students who switched majors and those who did not, nor can we observe considerable differences between the several groups of students switching majors (Table 1). The distribution of the individual occupational interests matching those most relevant for the originally chosen major indicates that $51.3 \%$ of the student population achieves a very good match (values above the 75 th percentile). This implies that about half of the first-semester students chose majors in higher education that corresponded with their individual interests. However, we observe differences between the groups: students switching majors showed worse matches between their occupational interests and the content of their major $(25.7 \%)$ than those staying in their initial major (19.8\%). Among students switching majors, especially those switching at an early stage of study and those switching across subject groups, report bad matches between their individual interests and the one domain mostly taught in their initial major. Finally, parents and peers in general largely approve of the majors students have initially chosen

\footnotetext{
15 To check for possible mediating effects, we estimated stepwise models (see Tables 7 and 8 in the Online Appendix) since there is the possibility that control variables influence the relationship of our key variables. Results indicate that none of the observed empirical associations between the dependent and the various explanatory variables are influenced by the other explanatory or by the control variables. Moreover, we estimated group-differentiated models for gender, migration background, parental education background, and vocational training to check for moderating effects (see Table 9 in the Online Appendix). Effects for the explanatory variables are mostly similar in direction and size for the different groups, yet not always significant, which is also the result of varying sample sizes. Overall, these results speak against the prevalence of mediator and moderator effects.
} 


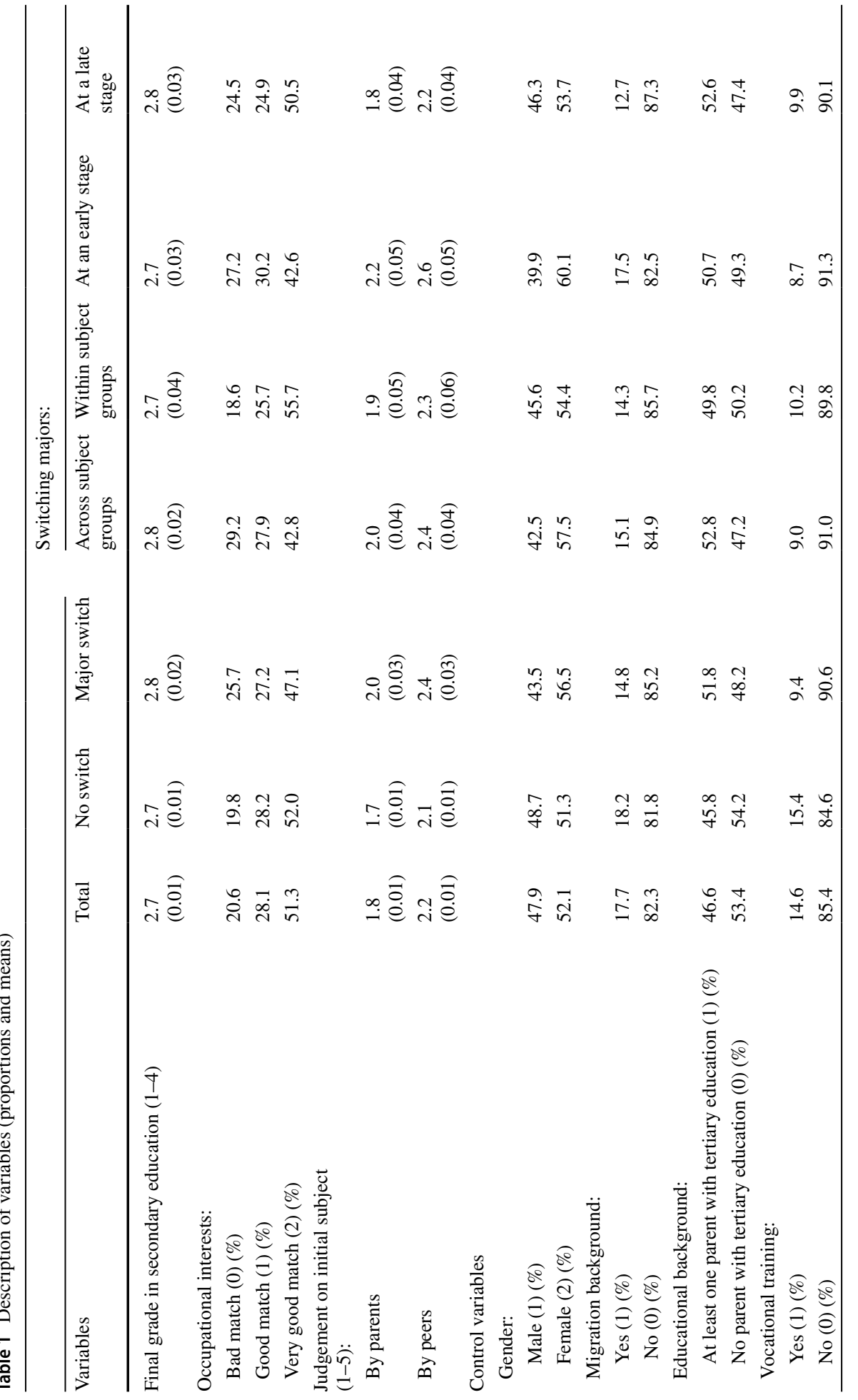




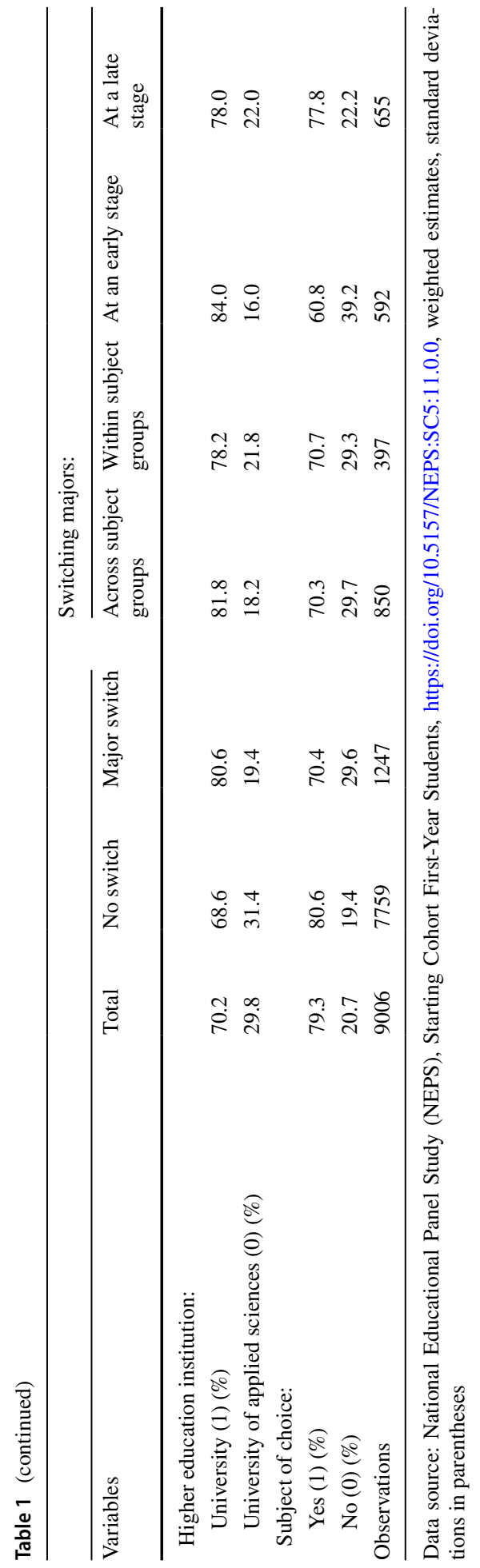


(mean value of 1.8), although peer judgements are a bit more negative than those of parents (mean value of 2.2). Again, students changing their subject and especially those changing across broad subject categories and at an early stage of their studies receive lower levels of support from both parents and peers.

As a next step, we estimated logistic regression models on the five different dependent variables. Figure 1 presents the results on switching majors as a transfer to another major among any of the 78 subject categories, irrespective of whether the change took place within or across broad subject groups or at an early or late stage. In Fig. 2, we take the degree of switching majors into account and differentiate between switching majors across and within broad subject groups. Finally, Fig. 3 presents the models, distinguishing between those students switching majors at an early stage of study and those doing so at a later stage. Coefficients are displayed as average marginal effects (AMEs) with 95\% confidence intervals. All models contain control variables (gender, migrant and educational background, vocational training, higher education institution, and subject of choice).

As we expected from Hypothesis $1 \mathrm{~b}$, better final grades in upper secondary education do increase the probability of switching majors (Fig. 1). This effect is even higher when students switch across broad subject groups (Fig. 2) and, other than expected, when students switch their major at a late stage of their study (Fig. 3). These results are in contrast with our Hypothesis 1a and previous findings for other countries (AstorneFigari \& Speer, 2019; Belloc et al., 2011; Hovdhaugen, 2009), according to which better academic performance lowers the probability of switching majors. On the one hand, we interpret this finding against the background of the German higher education system, where access to higher education often depends on the grades of the higher education entry qualification. As a consequence, students with higher achievement in secondary education have more options to choose from and thus better probabilities of success in a large variety of subjects (even at later points during their studies). On the other hand, this result might also stem from our operationalization, since we do not measure performance in higher education (as studies in other country contexts did). Accordingly, students with lower achievement in secondary education might perform well in their initially chosen subject and are thus less likely to switch their major.

Regarding the occupational interests of students, one can see that a (very) good match with the content taught in their originally chosen major is related to a decreased risk of switching majors. While the effect of this variable is not significant for subject changes in general $(\mathrm{p}<0.05$; Fig. 1), it increases and turns significant for subject changes across broad subject groups (Fig. 2). In contrast, (mis)matching occupational interest does not seem to matter for subject changes within broad disciplines and for the timing of switching majors (Fig. 3). Overall, these results indicate that a (very) good match between students' occupational interests and the content taught in their major increases the chances of staying with their initially chosen subject, thus lowering the probability of switching majors. We can therefore confirm Hypothesis 2 for substantial switching of majors across broad subject groups.

Regarding social costs, we expected negative parental and peer judgements about the initially chosen subject to increase the probability of switching majors (Hypothesis 3). Our models support this hypothesis, since students show a higher probability of switching majors the more their parents and peers disapprove of their initial subject choice (Fig. 1). This is true for both changes within and across subject groups (Fig. 2) but stronger effects are found for changes across academic disciplines, which implies that the possible sanctions of such nonconforming behavior might be stronger than for subject changes within subject groups. Moreover, results confirm that parental and peer disapproval of the originally chosen major is particularly important for changing majors at an early stage of higher 


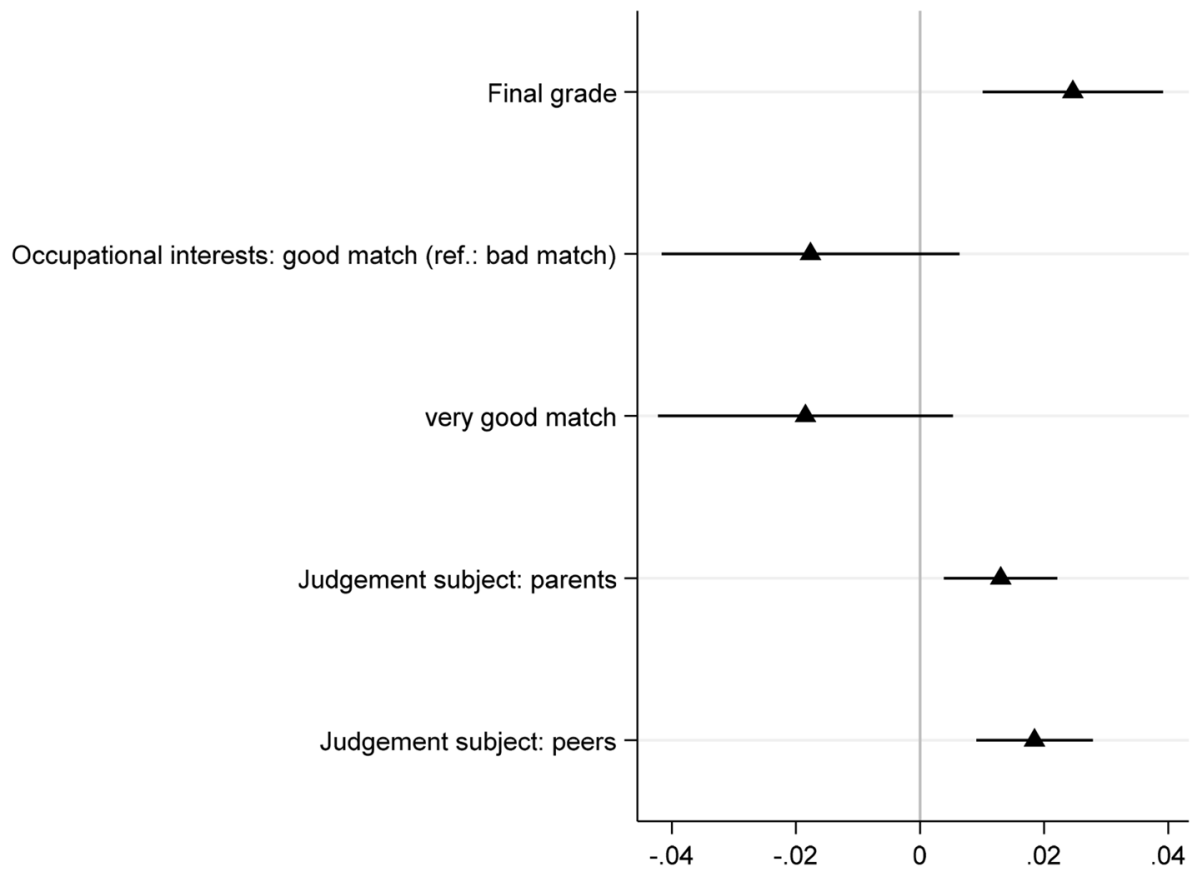

Fig. 1 Results from logistic regression: switching majors in general (AMEs with 95\% confidence intervals). Data source: National Educational Panel Study (NEPS), Starting Cohort First-Year Students, https://doi.org/ 10.5157/NEPS:SC5:11.0.0, weighted estimates, $\mathrm{N}=9006$ (7759 non-switchers and 1247 subject-switchers)

education (Fig. 3). At a later stage, parental and peer evaluations might lose their importance due to social networks formed within higher education itself, which are not captured by the variables. The results of the stepwise inclusion of variables (see Table 7 in the Online appendix) indicate that models on parental and peer expectations exhibit better model fits, which implies that these factors are more important for understanding major switches than individual achievements or person-major fits.

The results of the control variables (see Table 6 in the appendix) indicate that women have a higher probability of switching majors than men do, which supports the results of Astorne-Figari and Speer (2018) for the US and Belloc et al. (2011) for Italy. Having completed vocational training before studying and a migrant background decrease the risk of switching majors, which is also in line with previous research (Belloc et al., 2011; Ishitani \& Flood, 2018; Tieben, 2020). Interestingly, first-generation students (i.e. neither parent holds a tertiary education degree) also have a lower probability of switching majors, especially across subjects and at later stages, which contrasts with previous findings for the US (Ishitani \& Flood, 2018) and Italy (Belloc et al., 2011). This might either be due to different measures of parental background, since both other studies use parental income instead of education. However, the result might also be specific to the German context, since state subsidies for students of low-income families are only paid if switching majors takes place during the first three terms, which makes especially later switches costlier. Finally, students at universities have a higher probability of switching majors than students studying at a university of applied sciences, while students enrolled in their preferred major are less likely to do so, which supports findings on students' dropout (Ishphording \& Wozny, 2018; Isleib et al., 2019). 


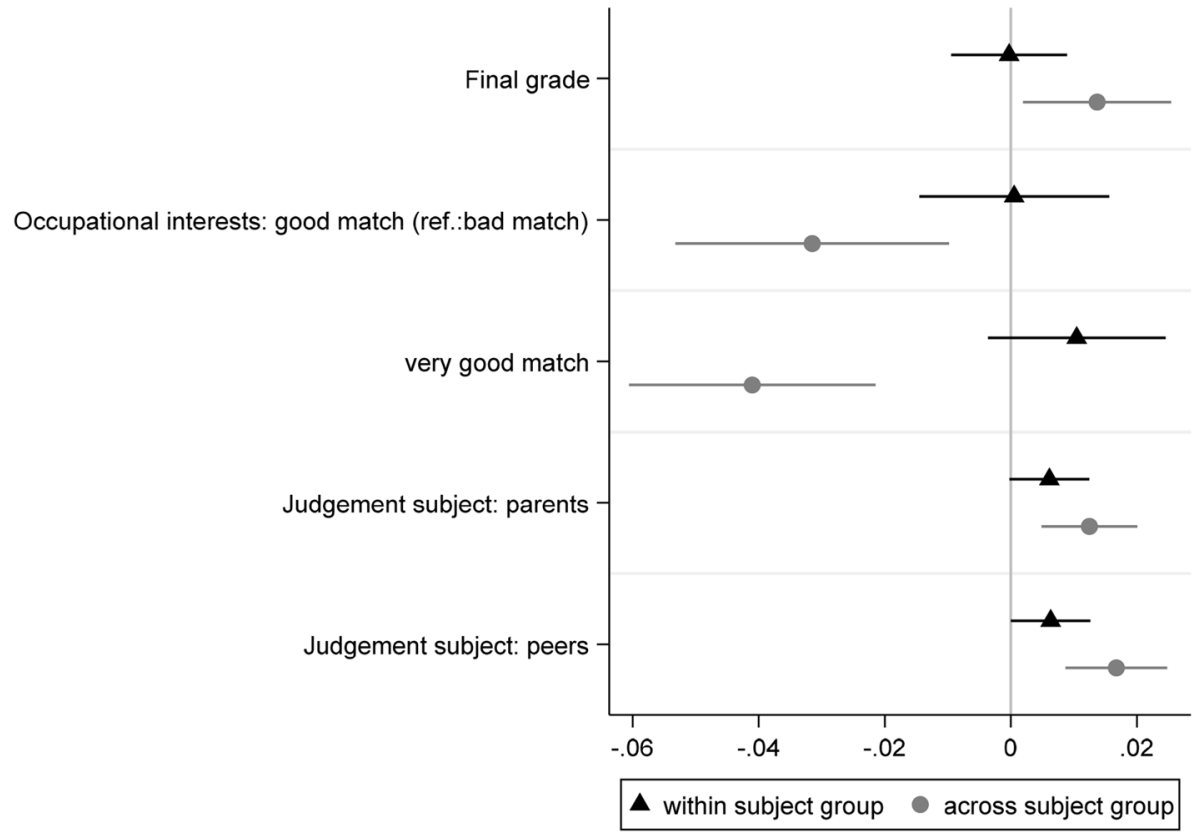

Fig. 2 Results from logistic regression: switching majors within and across subject groups (AMEs with 95\% confidence intervals). Data source: National Educational Panel Study (NEPS), Starting Cohort FirstYear Students, https://doi.org/10.5157/NEPS:SC5:11.0.0, weighted estimates, $\mathrm{n}=8609$ (7759 non-switchers, 850 subject-switchers across subject groups); $n=8156$ (7,759 non-switchers, 397 subject-switchers within subject groups)

\section{Conclusion}

In this article, we examined how aspects of individual achievement, person-major fit, and parental and peer expectations affect students switching majors in German higher education and whether these effects vary between the degree and timing of such switches. Theoretically, we applied a rational choice approach according to which students consider their probabilities of success in the initial major and weigh the anticipated benefits and costs of staying versus leaving. Thus, we perceive switching majors as a revision of the initial subject choice, which was made under incomplete information. Empirically, however, we were not able to measure the broad concepts of probability of success, benefits, and costs. Rather, the data used allowed us only to consider certain aspects of these concepts: student's school achievement to affect the probability of success, a good match between individual occupational interests and the interests met by particular subjects as a possible benefit, and parental and peer approval of the initial subject as lowering social costs.

Overall, the empirical analyses based on a representative sample of German students starting higher education in 2010/11 support our theoretical considerations. First, students' individual performance evaluations in the form of the final grades received in upper secondary education matter in this regard. In contrast to previous studies in different country contexts (Astorne-Figari \& Speer, 2019; Belloc et al., 2011; Hovdhaugen, 2009), our results indicate that better academic performance increases the probability of switching majors. This might be particularly the case in the German higher education system, where 


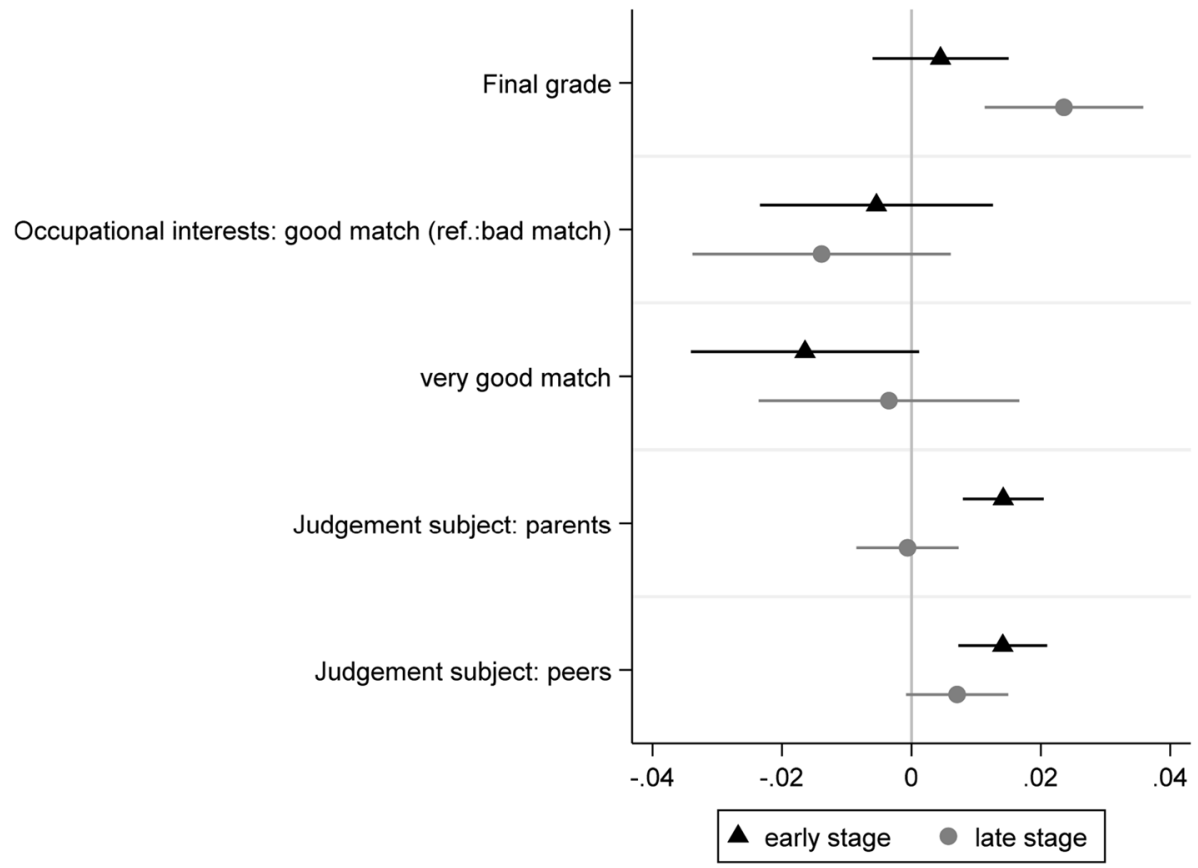

Fig. 3 Results from logistic regression: switching majors at an early or at a late stage (AMEs with 95\% confidence intervals). Data source: National Educational Panel Study (NEPS), Starting Cohort First-Year Students, https://doi.org/10.5157/NEPS:SC5:11.0.0, weighted estimates, $\mathrm{n}=8351$ (7759 non-switchers, 592 subject-switchers at an early stage); $\mathrm{n}=8414$ ( 7759 non-switchers, 655 subject-switchers at a late stage)

access to many subjects depends on a student's achievements in secondary education. As a consequence, high-performing students have more options to choose from and thus have a better probability of success in a large variety of subjects, while students with lower grades have to stick to their initial choice. Since we were only able to measure performance in terms of high school grades, further research should establish whether performance in higher education produces similar results in the German context, or whether it is more in line with previous international research suggesting a higher inclination for students with lower performance to switch majors.

Regarding the person-major fit as an aspect of benefits, we investigated the (mis)match between individual occupational interests and the content of the subject initially chosen. A better match should increase the benefit of studying a particular subject, making switches less likely. We confirmed this assumption for switching majors across broad subject groups, but it did not matter for changes within subject groups; nor did it matter for the timing of switching major. This finding points toward the importance of differentiating between the degrees of change, as we did in our study. Subject characteristics may not only matter regarding the initial subject; they may also matter regarding the major students choose to switch to.

A limitation in this regard is the operationalization of the match between the occupational interests of the student and the contents taught in the field of study. We followed Bergmann and Eder (1999) and Nagy (2007), who identified the occupational interest which is the most relevant in each field of study. Since the substantive focus of a field of study can differ between institutions of higher education and can therefore cater to 
occupational interests at different levels, a precise measurement of the environment characteristics would have been a better indicator.

Finally, perceived parental and peer support of the initial subject choice as an aspect of the social environment lowers the risk of switching majors, especially when those switches happen at an early stage of study and correlate with a transfer across subject groups. This confirms earlier findings (Raabe et al., 2019) that young adults value their friends' opinions and discuss their subject preferences and points toward the importance of costs relating to switching majors.

Due to our study design, we could only consider perceived parental and peer expectations at higher education entry, while social processes taking place in the course of higher education studies could not be investigated. Accordingly, future research should examine further social influences that might be useful for understanding later switches, such as social integration with fellow students or teaching personnel. These aspects have been shown to matter for student dropout (e.g. Klein, 2019), while the relevance for switching majors is yet to be established.

Overall, this study makes three important contributions to understanding the underresearched topic of switching majors in higher education. It is the first study that systematically integrates explanations relating to the individual, the subject, and the social level into one theoretical framework and that simultaneously examines their effect on switching majors. Results indicate that all of these aspects matter, with parental and peer judgement being slightly more important than individual achievement and person-major fit. But our findings highlight as well that results might be sensitive to the country context. Thus, in countries where subject choices are bound to institutional restrictions, such as in Germany (Finger et al., 2018), major switches might be driven by different factors than in countries with open major choice systems, such as the US (Bordon \& Fu, 2015; Bridet \& Leighton, 2015; Wright, 2018). The effect of individual achievements is one example of how explanatory factors might vary, which calls for more comparative research on this topic.

Second, our results demonstrate that it is important to differentiate between the degree and the timing of switching majors, since not all changes seem to be major changes (Astorne-Figari \& Speer, 2019). Our research confirms that the phenomenon of switching majors is highly heterogeneous in the sense that it comprises minor adjustments within the same area but also major changes between different groups of study. Also, the timing of switching majors seems to matter in the sense that early decisions regarding changing majors seem to be driven by other factors than decisions for late changes. Mixing up such different phenomena is likely to lead to contradictory research results.

Finally, we can show that, although switching majors is driven partly by forces similar to those driving dropout rates, it is a distinct phenomenon in terms of explanatory factors and further research should treat it as such. Overall, we can conclude that the practice of switching majors (other than dropout from higher education) has not yet received enough research attention to understand this diverse phenomenon sufficiently. We hope, however, that this study contributes to increasing the understanding of this complex issue.

\section{Appendix}

See Tables 2-6 


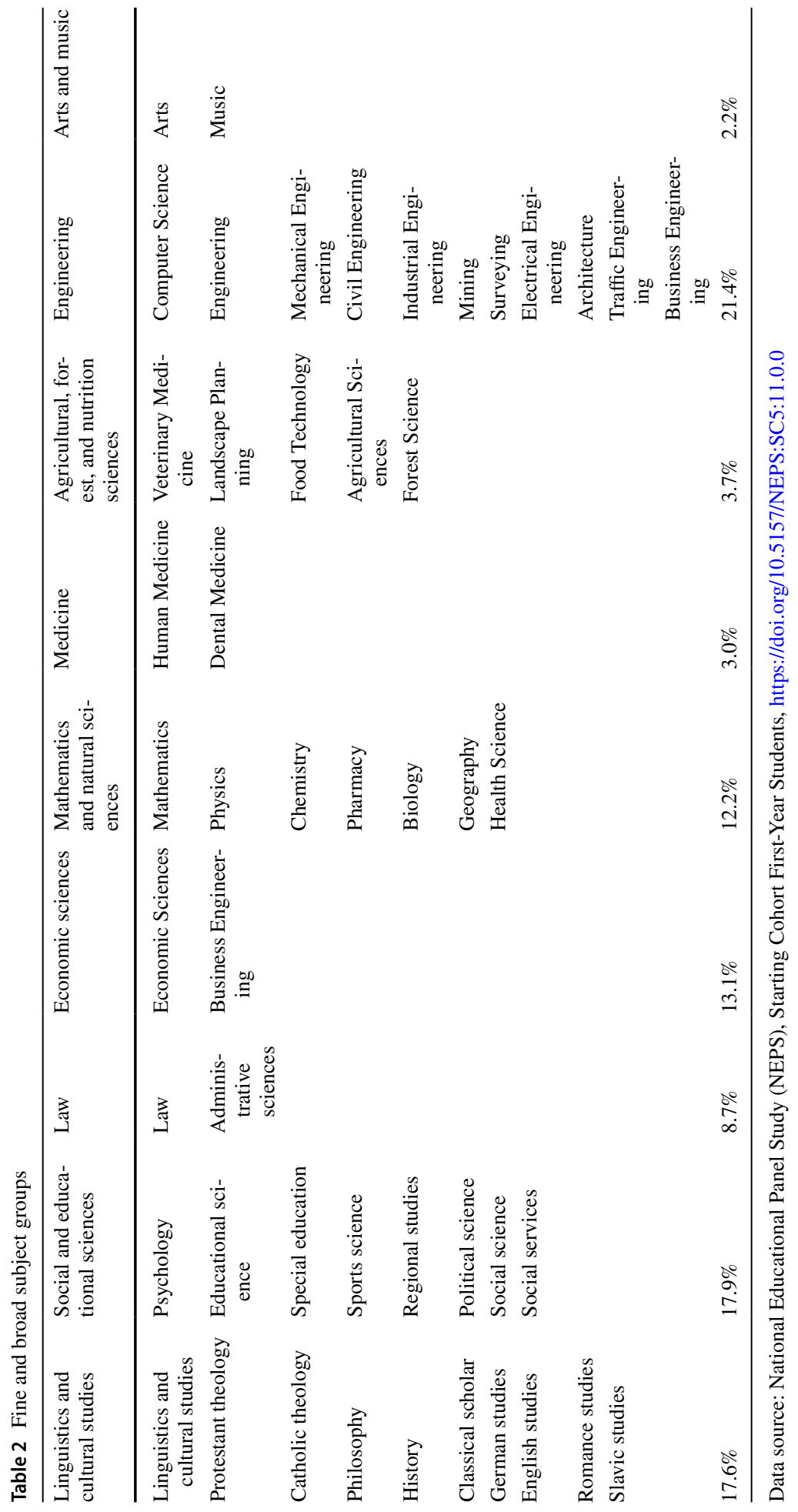




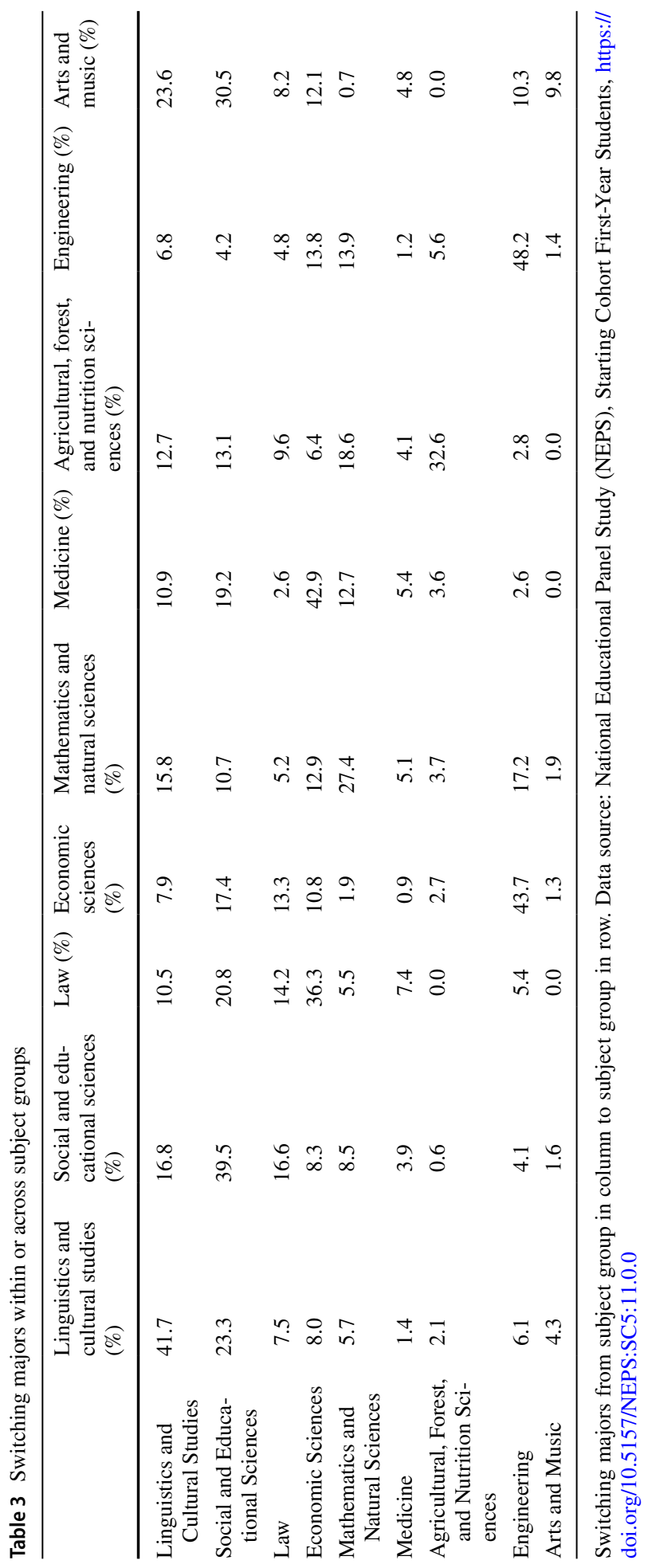




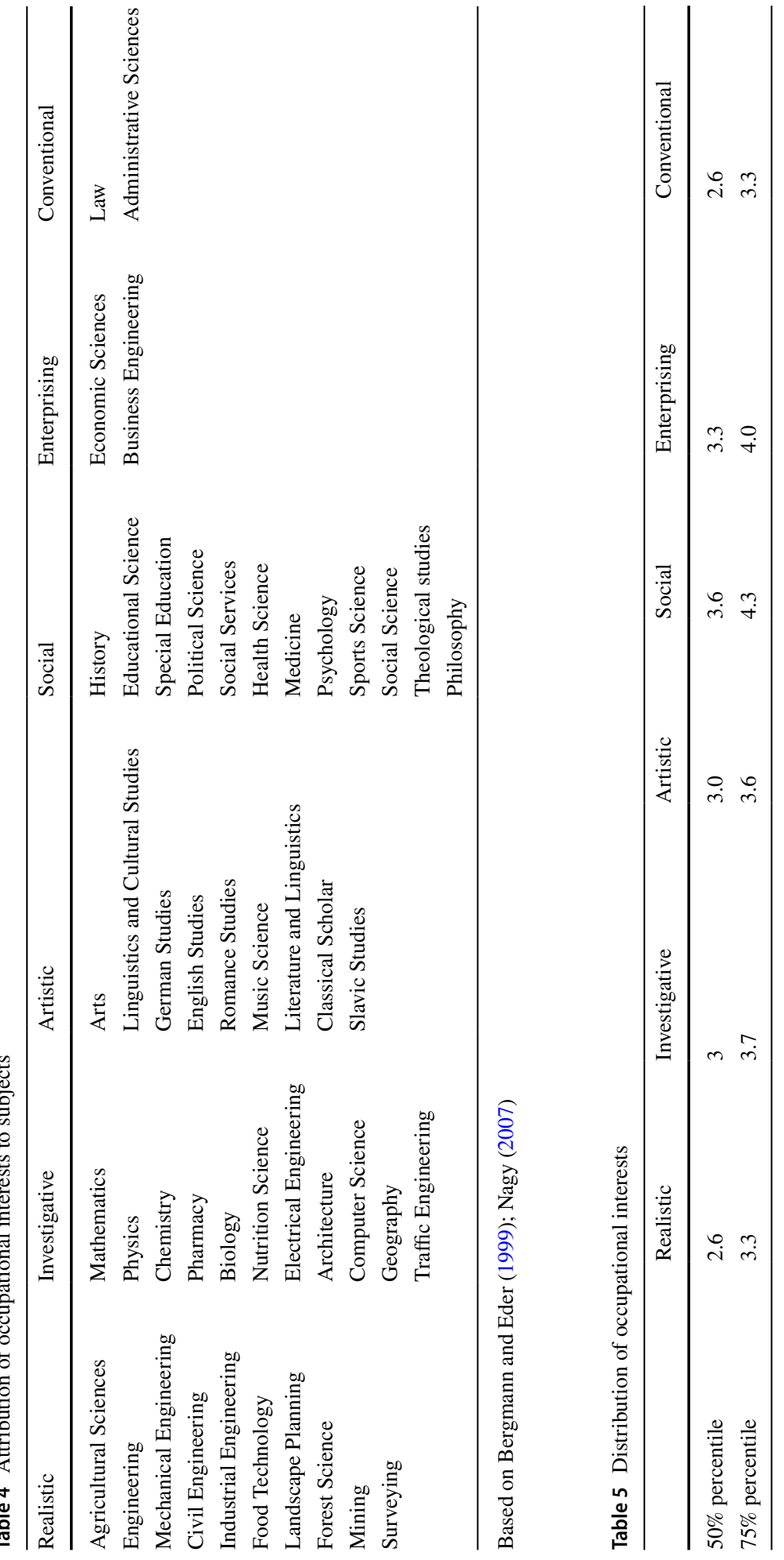




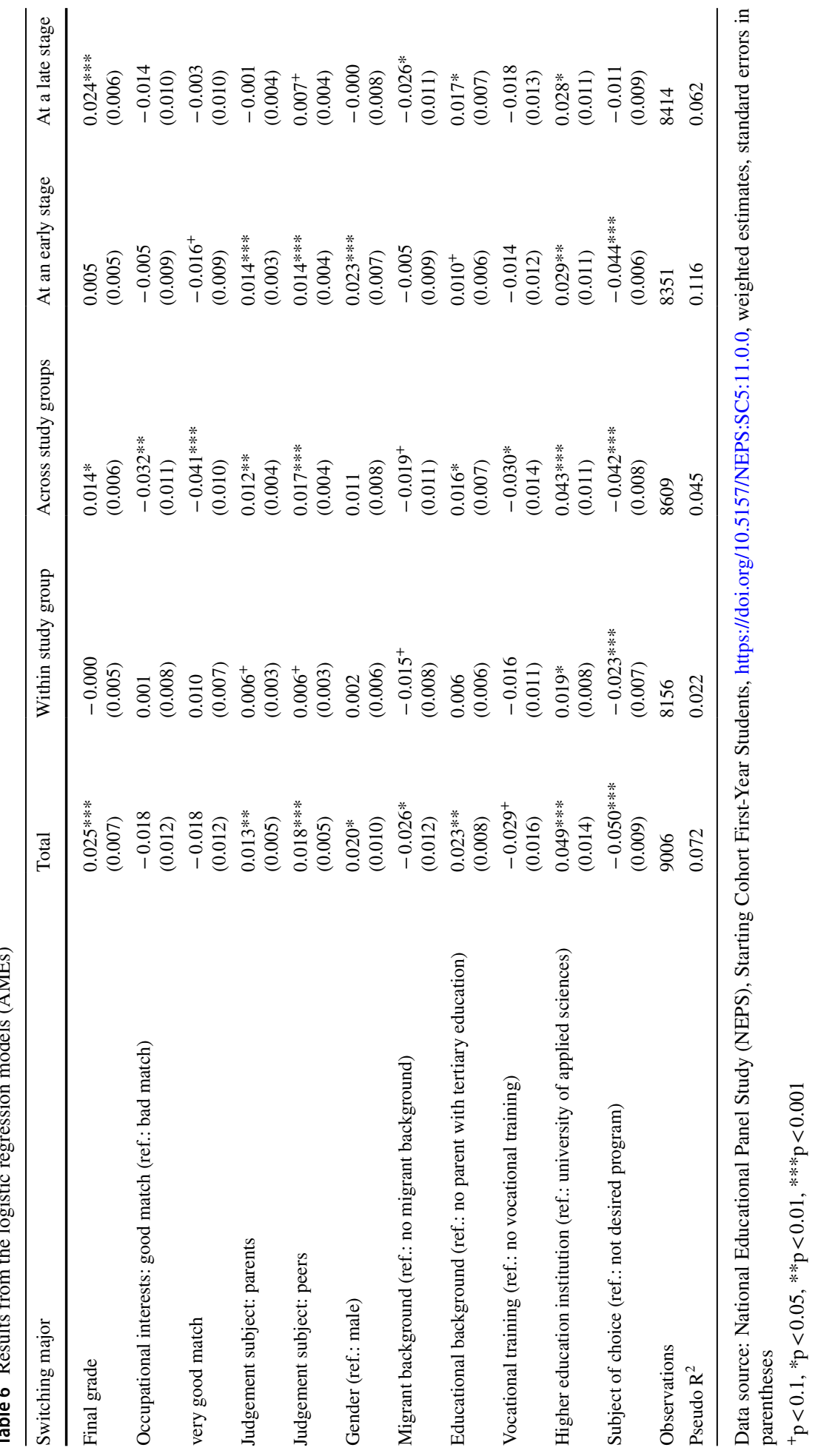


Supplementary Information The online version contains supplementary material available at https://doi. org/10.1007/s11162-021-09650-y.

Funding Open Access funding enabled and organized by Projekt DEAL. German Federal Ministry of Education and Research (BMBF), (project no. 01FP13042E).

\section{Declarations}

Conflict of interest The authors declare that they have no conflict of interest.

Open Access This article is licensed under a Creative Commons Attribution 4.0 International License, which permits use, sharing, adaptation, distribution and reproduction in any medium or format, as long as you give appropriate credit to the original author(s) and the source, provide a link to the Creative Commons licence, and indicate if changes were made. The images or other third party material in this article are included in the article's Creative Commons licence, unless indicated otherwise in a credit line to the material. If material is not included in the article's Creative Commons licence and your intended use is not permitted by statutory regulation or exceeds the permitted use, you will need to obtain permission directly from the copyright holder. To view a copy of this licence, visit http://creativecommons.org/licenses/by/4.0/.

\section{References}

Allen, J., \& Robbins, S. B. (2008). Prediction of college major persistence based on vocational interests, academic preparation, and first-year academic performance. Research in Higher Education, 49, 62-79.

Allen, J., \& Robbins, S. (2010). Effects of interest-major congruence, motivation, and academic performance on timely degree attainment. Journal of Counseling Psychology, 57(1), 23-35.

Altonji, J. G., Blom, E., \& Meghir, C. (2012). Heterogeneity in human capital investments: High school curriculum, college major, and careers. Annual Review of Economics, 4(1), 185-223.

Arcidiacono, P. (2004). Ability sorting and the returns to college major. Journal of Econometrics, 121(1-2), 343-375.

Astorne-Figari, C., \& Speer, J. D. (2018). Drop out, switch majors, or persist? The contrasting gender gaps. Economics Letters, 164, 82-85.

Astorne-Figari, C., \& Speer, J. D. (2019). Are changes of major major changes? The roles of grades, gender, and preferences in college major switching. Economics of Education Review, 70, 75-93.

Becker, R., Haunberger, S., \& Schubert, F. (2010). Studienfachwahl als Spezialfall der Ausbildungsentscheidung und Berufswahl. Zeitschrift Für ArbeitsmarktForschung, 42, 292-310.

Belloc, F., Maruotti, A., \& Petrella, L. (2011). How individual characteristics affect university students' drop-out: A semiparametric mixed-effects model for an Italian case study. Journal of Applied Statistics, 38(10), 2225-2239.

Bergmann, C., \& Eder, F. (1999). Allgemeiner Interessen-Struktur-Test (AIST)/Umwelt-Struktur-Test (UST) (Manual 2nd Edition). Göttingen: Beltz.

Blossfeld, H.-P., Roßbach, H.-G., \& von Maurice, J. (Hrsg.) (2011). Education as a Lifelong Process - The German National Educational Panel Study (NEPS). Zeitschrift für Erziehungswissenschaft (Sonderheft 14).

Blüthmann, I., Lepa, S., \& Thiel, F. (2008). Studienabbruch und -wechsel in den neuen Bachelorstudiengängen. Zeitschrift Für Erziehungswissenschaft, 11(3), 406-429.

Bordon, P., \& Fu, C. (2015). College-major choice to college-then-major choice. Review of Economic Studies, 82(4), 1247-1288.

Bornmann, L., \& Daniel, H.-D. (1999). Der Wechsel des Studiengangs an der Universität Gesamthochschule Kassel-Ausmaß und Bedingungen. In M. Schröder-Gronostay, \& H.-D. Daniel (Eds.), Studienerfolg und Studienabbruch: Beiträge aus Forschung und Praxis (pp. 195-208). Kriftel: Luchterhand.

Bridet, L., \& Leighton, M. (2015). The major decision: Labor market implications of the timing of specialization in college. School of Economics and Finance Discussion Papers, 1510, 1-73.

Statistisches Bundesamt (2012). Bildung und Kultur. Studierende an Hochschulen. Wiesbaden: Statistisches Bundesamt.

Statistisches Bundesamt (2018). Bildung und Kultur. Nichtmonetäre hochschulstatistische Kennzahlen 1980-2017. Wiesbaden: Statistisches Bundesamt. 
Statistisches Bundesamt (2020). Bildung und Kultur. Studienverlaufsstatistik 2019. Wiesbaden: Statistisches Bundesamt.

Chai, S. K. (2001). Choosing an identity: A general model of preference and belief formation. University of Michigan Press.

Diem, A. (2016). Studienfachwechsel im Bologna-System. Eine Analyse der universitären Hochschulen der Schweiz. Aarau: SKBF 2016, 36 S. - (SKBF Staff Paper; 17).

Eccles, J. (2011). Gendered educational and occupational choices: Applying the Eccles et al. model of achievement-related choices. International Journal of Behavioral Development, 35(3), 195-201.

Eccles [Parsons], J., Adler, T. F., Futterman, R., Goff, S. B., Kaczala, C. M., Meece, J. L., \& Midgley, C. (1983). Expectations, values and academic behaviors. In J. T. Spence (Ed.), Perspective on achievement and achievement motivation (pp. 75-146). W. H. Freeman.

Eccles, J. S. (1994). Understanding women's educational and occupational choices: Applying the Eccles et al. model of achievement-related choices. Psychology of Women Quarterly, 18, 585-609.

Erikson, R., \& Jonsson, J. O. (1996). Explaining class inequality in education: The Swedish case. In R. Erikson \& J. O. Jonsson (Eds.), Can education be equalized? The Swedish case in comparative perspective (pp. 1-63). Westview Press.

FDZ-LIfBi (2018). Data manual NEPS Starting Cohort 5 - first-year students: From higher education to the labor market, Scientific Use File version 11.0.0 (NEPS Research Data Documentation Series). Leibniz Institute for Educational Trajectories, National Educational Panel Study.

Fellenberg, F., \& Hannover, B. (2006). Kaum begonnen, schon zerronnen?: Psychologische Ursachenfaktoren für die Neigung von Studienanfängern, das Studium abzubrechen oder das Fach zu wechseln. Empirische Pädagogik, 20(4), 381-399.

Finger, C., Fitzner, C., \& Heinmüller, J. (2018). Von wegen" einfach einschreiben": Wie deutsche Hochschulen ihre Studierenden auswählen. WZBrief Bildung, No.37, Wissenschaftszentrum Berlin für Sozialforschung (WZB), Berlin.

Foraker, M. J. (2012). Does changing majors really affect the time to graduate? The impact of changing majors on student retention, graduation, and time to graduate. Western Kentucky State University, Office of Institutional Research.

Hägglund, A. E., \& Lörz, M. (2020). Warum wählen Männer und Frauen unterschiedliche Studienfächer? Zeitschrift Für Soziologie, 49(1), 66-86.

Heublein, U. (2014). Student drop-out from German higher education institutions. European Journal of Education, 49(4), 497-513.

Heublein, U., Ebert, J., Hutzsch, C., Isleib, S., König, R., Richter, J., et al. (2017). Zwischen Studienerwartungen und Studienwirklichkeit: Ursachen des Studienabbruchs, beruflicher Verbleib der Studienabbrecherinnen und Studienabbrecher und Entwicklung der Studienabbruchquote an deutschen Hochschulen. Forum Hochschule: Deutsches Zentrum für Hochschul- und Wissenschaftsforschung GmbH $(D Z H W)$.

Heublein, U., Richter, J., Schmelzer, R., \& Sommer, D. (2012). Die Entwicklung der Schwund- und Studienabbruchquoten an den deutschen Hochschulen. Statistische Berechnungen auf der Basis des Absolventenjahrgangs 2010. HIS: Forum Hochschule, 3/2012, 1-66.

Heublein, U., Schmelzer, R., Sommer, D., \& Wank, J. (2008). Die Entwicklung der Schwund und Studienabbruchquoten an den deutschen Hochschulen. Statistische Berechnungen auf der Basis des Absolventenjahrgangs 2006. HIS: Projektbericht Mai 2008, 1-78.

Holland, J. L. (1997). Making vocational choices: A theory of vocational personalities and work environments. Psychological Assessment Resources.

Hovdhaugen, E. (2009). Transfer and dropout: Different forms of student departure in Norway. Studies in Higher Education, 34(1), 1-17.

Ishitani, T. T., \& Flood, L. D. (2018). Student transfer-out behavior at four-year institutions. Research in Higher Education, 59, 825-846.

Ishphording, I., \& Wozny, F. (2018). Ursachen des Studienabbruchs - eine Analyse des Nationalen Bildungspanels. ISA Research Report, 82, 1-45.

Isleib, S., Woisch, A., \& Heublein, U. (2019). Ursachen des Studienabbruchs: Theoretische Basis und empirische Faktoren. Zeitschrift Für Erziehungswissenschaft, 22, 1047-1076.

Jonsson, J. O. (1999). Explaining sex differences in educational choice: An empirical assessment of a rational choice model. European Sociological Review, 15(4), 391-404.

King, B. (2015). Changing college majors: Does it happen more in STEM and do grades matter? Journal of College Science Teaching, 44(3), 44-51.

Klein, D. (2019). Das Zusammenspiel zwischen akademischer und sozialer Integration bei der Erklärung von Studienabbruchintentionen. Eine empirische Anwendung von Tintos Integrationsmodell im deutschen Kontext. Zeitschrift für Erziehungswissenschaft, 22(2), 301-323. 
Li, C., \& Kerpelman, J. (2007). Parental influences on young women's certainty about their career aspirations. Sex Roles, 56(1-2), 105-115.

Liu, V., Mishra, S., \& Kopko, E. M. (2021). Major Decision: The Impact of Major Switching on Academic Outcomes in Community Colleges. Research in Higher Education, 62(4), 498-527.

Lörz, M., Schindler, S., \& Walter, J. G. (2011). Gender inequalities in higher education: Extent, development and mechanisms of gender differences in enrolment and field of study choice. Irish Educational Studies, 30(2), 179-198.

Mann, A., \& DiPrete, T. A. (2013). Trends in gender segregation in the choice of science and engineering majors. Social Science Research, 42(6), 1519-1541.

Mann, A., \& DiPrete, T. A. (2016). The consequences of the national math and science performance environment for gender differences in STEM aspiration. Sociological Science, 3, 568-603.

Meyer, J., \& Strauß, S. (2019). The influence of gender composition in a field of study on students' drop-out of higher education. European Journal of Education, 54(3), 443-456.

Mood, C. (2010). Logistic regression: Why we cannot do what we think we can do, and what we can do about it. European Sociological Review, 26(1), 67-82.

Nagy, G. (2007). Berufliche Interessen, kognitive und fachgebundene Kompetenzen. Ihre Bedeutung für die Studienfachwahl und die Bewährung im Studium. Doctoral Dissertation, FU Berlin.

Ochsenfeld, F. (2016). Preferences, constraints, and the process of sex segregation in college majors: A choice analysis. Social Science Research, 56, 117-132.

OECD. (2019). Education at a Glance 2019. OECD indicators. OECD Publishing.

Ost, B. (2010). The role of peers and grades in determining major persistence in the sciences. Economics of Education Review, 29(6), 923-934.

Porter, S. R., \& Umbach, P. D. (2006). College major choice: An analysis of person-environment fit. Research in Higher Education, 47(4), 429-449.

Raabe, I. J., Boda, Z., \& Stadtfeld, C. (2019). The social pipeline: How friend influence and peer exposure widen the STEM gender gap. Sociology of Education, 92(2), 105-123.

Riegle-Crumb, C., King, B., \& Moore, C. (2016). Do they stay or do they go? The switching decisions of individuals who enter gender atypical college majors. Sex Roles, 74(9-10), 436-449.

Robbins, S. B., Lauver, K., Le, H., Davis, D., Langley, R., \& Carlstrom, A. (2004). Do psychosocial and study skill factors predict college outcomes? A meta-analysis. Psychological Bulletin, 30, 261-288.

Robinson, R. (2004). Pathways to completion: Patterns of progression through a university degree. Higher Education, 47, 1-20.

Schlücker, F., \& Schindler, S. (2019). Studienleistung im Bachelor-und Masterstudium. Bedingungsfaktoren und ihr Zusammenhang mit der sozialen Herkunft der Studierenden. In M. Lörz \& H. Quast (Eds.), Bildungs-und Berufsverläufe mit Bachelor und Master (pp. 225-272). Springer.

Severiens, S., \& Dam, Gt. (2012). Leaving college: A gender comparison in male and female-dominated programs. Research in Higher Education, 53(4), 453-470.

Steinwede, J., \& Aust, F. (2012). Methodenbericht NEPS Startkohorte 5 - CATI-Haupterhebung Herbst 2010. Bonn: infas Institut für angewandte Sozialwissenschaft GmbH.

Tieben, N. (2020). Non-completion, transfer, and dropout of traditional and non-traditional students in Germany. Research in Higher Education, 61, 117-141.

van de Werfhorst, H. G., de Graaf, N. D., \& Kraaykamp, G. (2001). Intergenerational resemblance in field of study in the Netherlands. European Sociological Review, 17(3), 275-293.

van de Werfhorst, H. G., Sullivan, A., \& Cheung, S. Y. (2003). Social class, ability and choice of subject in secondary and tertiary education in Britain. British Educational Research Journal, 29(1), 41-62.

Wolter, S. C., Diem, A., \& Messer, D. (2014). Drop-outs from Swiss Universities: An empirical analysis of data on all students between 1975 and 2008. European Journal of Education, 49(4), 471-483.

Wright, C. (2018). Choose Wisely. A Study of College Major Choice and Major Switching Behavior. Doctoral dissertation, Pardee RAND Graduate School.

Yue, H., \& Fu, X. (2017). Rethinking graduation and time to degree: A fresh perspective. Research in Higher Education, 58, 184-213.

Zinn, S., Steinhauer, H. W., \& Aßmann, C. (2017). Samples, weights, and nonresponse: The student sample of the national educational panel study (Wave 1 to 8). Neps Survey Papers, 18, 1-28.

Publisher's Note Springer Nature remains neutral with regard to jurisdictional claims in published maps and institutional affiliations. 